Schinzel

Catalogue of

Unbalanced Chromosome Aberrations in Man 

Albert Schinzel

\section{Catalogue of \\ Unbalanced \\ Chromosome Aberrations \\ in Man}

\begin{tabular}{|c|}
\hline \\
0 \\
$G$
\end{tabular}

Walter de Gruyter · Berlin · New York 1984 


\author{
Author \\ Prof. Dr. med. Albert Schinzel \\ Institute of Medical Genetics \\ Universitiy of Zürich \\ Rămistrasse 74 \\ CH-8001 Zürich \\ Switzerland
}

CIP-Kurztitelaufnahme der Deutschen Bibliothek

Schinzel, Albert:

Catalogue of unbalanced chromosome aberrations in man / Albert Schinzel. Berlin; New York: de Gruyter, 1983.

ISBN 3-11-008370-1

NE: HST

Library of Congress Cataloging in Publication Data

Schinzel Albert, 1944-

Catalogue of unbalanced chromosome aberrations in man.

Includes indexes.

1. Human chromosome abnormalities--Catalogs and collections. I. Title.

RB155.S29 $1983 \quad 616$ '042 $83 / 7645$

ISBN 3-11-008370-1

(C) Copyright 1983 by Walter de Gruyter \& Co., Berlin 30.

All rights reserved, including those of translation into foreign languages. No part of this book may be reproduced in any form - by photoprint, microfilm or any other means nor transmitted nor translated into a machine language without written permission from the publisher. Printing: Gerike GmbH, Berlin. - Binding: Dieter Mikolai, Berlin. Printed in Germany. 